\title{
A case of sirenomelia-sympus monopus
}

\author{
*Rajkumar Motiram Meshram ${ }^{1}$, Nikila R ${ }^{1}$, Amruta Phatak ${ }^{1}$ \\ Sri Lanka Journal of Child Health, 2019; 48(3): 277-278 \\ DOI: http://dx.doi.org/10.4038/sljch.v48i3.8771 \\ (Key words: mermaid deformity, oligohydramnios, sirenomelia).
}

\section{Introduction}

Sirenomelia (mermaid deformity) consists of varying degrees of lower limb fusion and was first described by Rocheus in 1542 who named it after mythical Greek sirens ${ }^{1}$. The worldwide incidence is 0.8-1 case in 100,000 live births, the male to female ratio being $3: 1^{2}$. It is usually associated with multiple anomalies of the gastrointestinal, genitourinary, cardiovascular and musculoskeletal systems $^{2}$. Here we describe a rare case of sirenomelia sympus monopus.

\section{Case report}

A $750 \mathrm{~g}$ early preterm baby was born by spontaneous vaginal delivery to a 25 year old gravida 3 para 1 mother who had one abortion. The marriage was non-consanguineous and the mother was from a low socioeconomic class. She attended the antenatal clinic regularly and received iron, folic acid and calcium supplementation. Prenatal ultrasound was suggestive of severe oligohydramnios. She had no history of pregnancy induced hypertension, pre-gestational or gestational diabetes. There was no history of smoking or tobacco chewing. There was a history of first trimester abortion but there was no family history of fetal anomalies. Apgar score was 0 at first and fifth minutes of life. Respiratory efforts after birth were poor. The baby could not be salvaged and died within 30 minutes of birth.

On examination, baby had flattened facies, microcephaly, high arched palate, fused eyelids and malformed ears. Baby exhibited only the right upper limb with deformed forearm and hand and only the limb bud of left upper limb. The left lower limb demonstrated deformity of the leg and foot mimicking a tail with absent right lower limb and pelvic girdle (Figure 1).

${ }^{1}$ Government Medical College Nagpur, India

*Correspondence: dr_rajmeshram@rediffmail.com (iD)

orcid.org/ 0000-0003-3214-188X

(Received on 01 March 2018: Accepted after revision on 20 April 2018)

The authors declare that there are no conflicts of interest

Personal funding was used for the project.

Open Access Article published under the Creative

Commons Attribution CC-BY

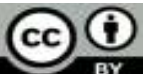

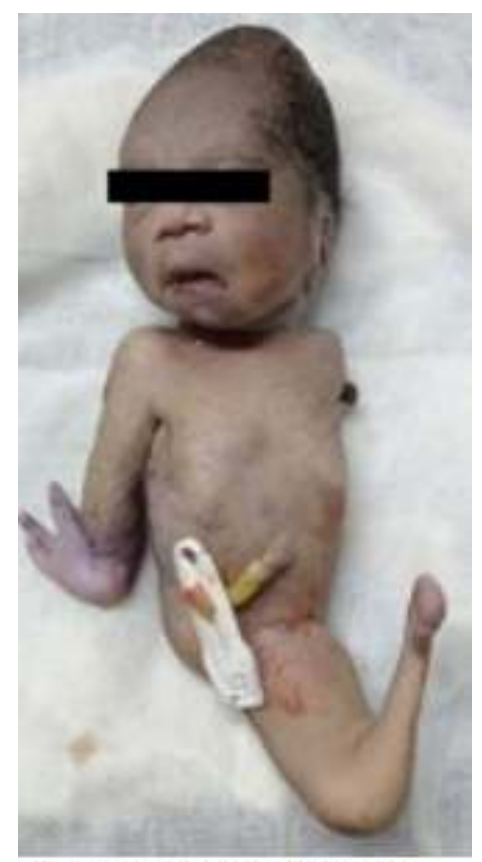

Figure 1: Mermaid deformity

Anal opening and external genitalia were absent, and baby also had a single umbilical artery. Radiograph of the baby showed absent radius in the right upper limb and absent fibula in left lower limb (Figure 2).

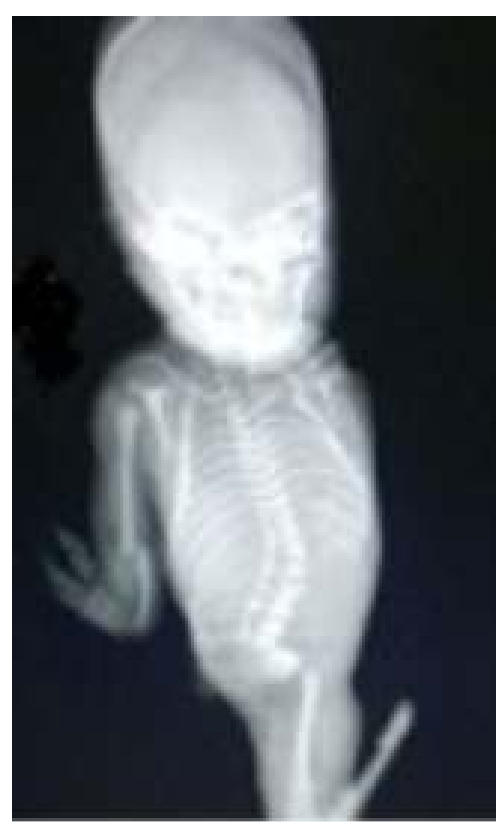

Figure 2: Radiograph of baby 


\begin{abstract}
Discussion
Sirenomelia was originally divided into 3 categories depending on the number of feet present: sympus apus (no feet), sympus monopus (one foot) and sympus dipus (both feet) ${ }^{3}$. This case belongs to the sympus monopus category. A better categorisation is that of Stocker and Heifetz in which seven types are defined ${ }^{4}$ : I (all thigh and leg bones present), II (single fibula), III (absent fibulae), IV (partially fused femurs, fused fibulae), $\mathrm{V}$ (partially fused femurs, absent fibulae), VI (single femur, single tibia) and VII (single femur, absent tibiae). This case belongs to category VI. The aetiology of this anomaly remains unclear. Whilst death is the usual outcome, as in our patient, survivals have been reported ${ }^{5,6,7}$. A study by Orioli et $a l^{8}$ found that $50 \%$ cases of sirenomelia were associated with genital, large intestinal, and urinary defects and 10-15\% with lower spinal column defects, single umbilical artery, upper limb, cardiac, and central nervous system defects. In our patient, the anal opening and external genitalia were absent, and baby also had a single umbilical artery. Radiograph of the baby showed absent radius in the right upper limb. However, organ anomalies could not be ruled out as autopsy was not done.
\end{abstract}

\section{References}

1. Kshirsagar VY, Ahmed M, Colaco SM. Sirenomelia apus: a rare deformity. Journal of Clinical Neonatology 2012; 1:146-8.

https://doi.org/10.4103/2249-4847.101699

PMid: 24027712 PMCid: PMC3762023

2. Reddy KR, Srinivas S, Kumar S, Reddy S, Hari Prasad, Irfan GM. Sirenomelia a rare presentation. Journal of Neonatal Surgery 2012; 1(1):7.

PMid: 26023366 PMCid: PMC4420302

3. Foerster A. Die Missbildungen des Menschen, nebst einem Atlas (German) Manke: Jena Friedrich; 18611865.
4. Stocker JT, Heifetz SA. Sirenomelia, a morphological study of 33 cases and review of the literature. Perspectives in Pediatric Pathology 1987; 10:7-50. PMid: 3588246

5. Murphy JJ, Fraser GC, Blair GK. Sirenomelia: case of the surviving mermaid. Journal of Pediatric Surgery 1992; 27(10):1265-8. https://doi.org/10.1016/00223468(92)9027 $0-\mathrm{H}$

6. Stanton MP, Penington EC, Hutson JM. A surviving infant with sirenomelia (mermaid syndrome) associated with absent bladder. Journal of Pediatric Surgery 2003; 38(8):1266-8. https://doi.org/10.1016/S00223468(03)00 286-0

7. Clarke LA, Stringer DA, Fraser GC, Yong SL. Long term survival of an infant with sirenomelia. American Journal of Medical Genetics 1993; 45(3):292-6.

https://doi.org/10.1002/ajmg.1320450303 PMid: 8434614

8. Orioli IM, Amar E, Arteaga -Vazquez J, Bakker MK, Bianca S, Botto LD, et al. Sirenomelia: an epidemiologic study in a large dataset from the International Clearinghouse of Birth Defects Surveillance and Research, and literature review. American Journal of Medical Genetics Part C: Seminars in Medical Genetics 2011; 157(4):358-73.

https://doi.org/10.1002/ajmg.c.30324

PMid: 22002878 PMCid: PMC4492125 